\title{
Impacted Lower First Molar and Labial Ectopic Upper Canine Eruption in an Individual from the Prehistoric American Southwest
}

\author{
Greg C. Nelson \\ Department of Anthropology, University of Oregon, Eugene, Oregon 97403-1218
}

\begin{abstract}
Tooth impactions and other positional anomalies are commonly encountered in clinical situations but are much less frequently seen in, or reported from, prehistoric archaeologically derived contexts. This report examines the occurrence of two positional anomalies, lower first molar impaction and upper canine labial ectopic eruption, in a single individual from the Ancestral Pueblo Gallina Phase (1100-1275 AD) of northern New
\end{abstract}

Although probably occurring in frequencies similar to those found in modern clinical samples, eruption disturbances are rarely reported from archaeologically derived skeletal series. Several factors lead to this underreporting including lack of recognition by workers unfamiliar with dental anatomy and eruptive processes and the associated fact that low natural occurrence frequencies lead to extreme rarity in the often small population samples anthropologists commonly study. In addition, when eruptive disturbances are found they frequently appear in a single individual so have little evolutionary or predictive value.

However, when two eruption disturbances, affecting both mandible and maxilla and different tooth classes, appear in a single individual further investigation and reporting is warranted, particularly when one is considered quite rare by clinical standards. In this short communication I explore a case of lower first molar impaction in an individual from the Ancestral Puebloan Gallina phase of north central New Mexico dating to approximately 750 years ago. This individual also expresses labial ectopic alveolar eruption of the left maxillary canine.

According to Pindborg (1970) and Andreasen et al. (1997) impaction of the lower first molar is the rarest of eruptive disturbances with occurrence frequencies reported to be between 0.00 and 0.063 percent (Dachi and Howell, 1961; Kramer and Williams, 1970; Shah et al., 1978; Grover and Lorton, 1985). Because of its rarity, documentation and description of LM1 impaction in an individual from a prehistoric context may shed some light on the etiology of the anomaly and its developmental background.
Mexico. Although outwardly dissimilar, appearing as they do in different tooth classes and both the mandible and maxilla, their underlying similarity implies a common etiology. The co-occurrence of these anomalies presents an opportunity to explore the etiological basis of positional anomalies and possibly provide some insight into the very early stages of dental morphogenesis. Dental Anthropology 23(3):79-82.

In contrast to $M_{1}$ impaction, ectopic eruption of maxillary canines is relatively common at least among positional developmental anomalies. The maxillary canine is one of the most frequently malerupted teeth and palatal and labial ectopic eruption is well documented (Pindborg, 1970; Peck et al., 1994; Becker and Chaushu, 2000; Chaushu et al., 2003; Camilleri et al., 2008). In addition, transposition of maxillary canines and third premolars is one of the best documented dental anomalies among prehistoric skeletal series (Nelson, 1992; Burnett and Weets, 2001).

\section{Context of the Burial}

The Gallina were an Ancestral Pueblo group who occupied a fairly restricted geographic area of northern New Mexico during the Pueblo III period (approximately 1100-1300 AD). Centered in the Llaves valley the Gallina were maize horticulturalists who were greatly impacted by extended droughts of the thirteenth century and who disappear between 1260 and 1300 AD (Ellis, 1988; Crown et al., 1996). The BMG site is an unexcavated habitation site occupying a small ridge on the western flanks of the Llaves valley that was surveyed during summer 2006. During this survey a skeleton was discovered eroding out just west of the ridge top and collected. The individual, BMG-1, is a female of approximately 19-23 years of age based on dental wear and tooth eruption and iliac crest

Correspondence to: Greg C. Nelson, Department of Anthropology, University of Oregon, Eugene, Oregon 97403-1218

E-mail: gcnelson@uoregon.edu 
fusion (Buikstra and Ubelaker, 1994; Bass, 1995). Upon curation and cleaning in the lab four skeletal elements representing a neonate were discovered (BMG-1a).

\section{Description of gnathic elements}

Dental and gnathic remains of BMG-1 include most of the mandible, the left maxilla, and three isolated maxillary teeth. The mandibular corpus (Fig. 1) is broken in the right premolar area such that the posterior portion of the right corpus does not connect with the remainder of the mandible although both $\mathrm{RP}_{3}$ and $\mathrm{RP}_{4}$ are present. The anterior portion of the $\mathrm{RP}_{3}$ socket remains allowing correct placement of this tooth within the arcade. All teeth are present except for $\mathrm{LM}_{3^{\prime}} \mathrm{RM}_{2^{\prime}}$ and $\mathrm{RM}_{3}$. The sockets
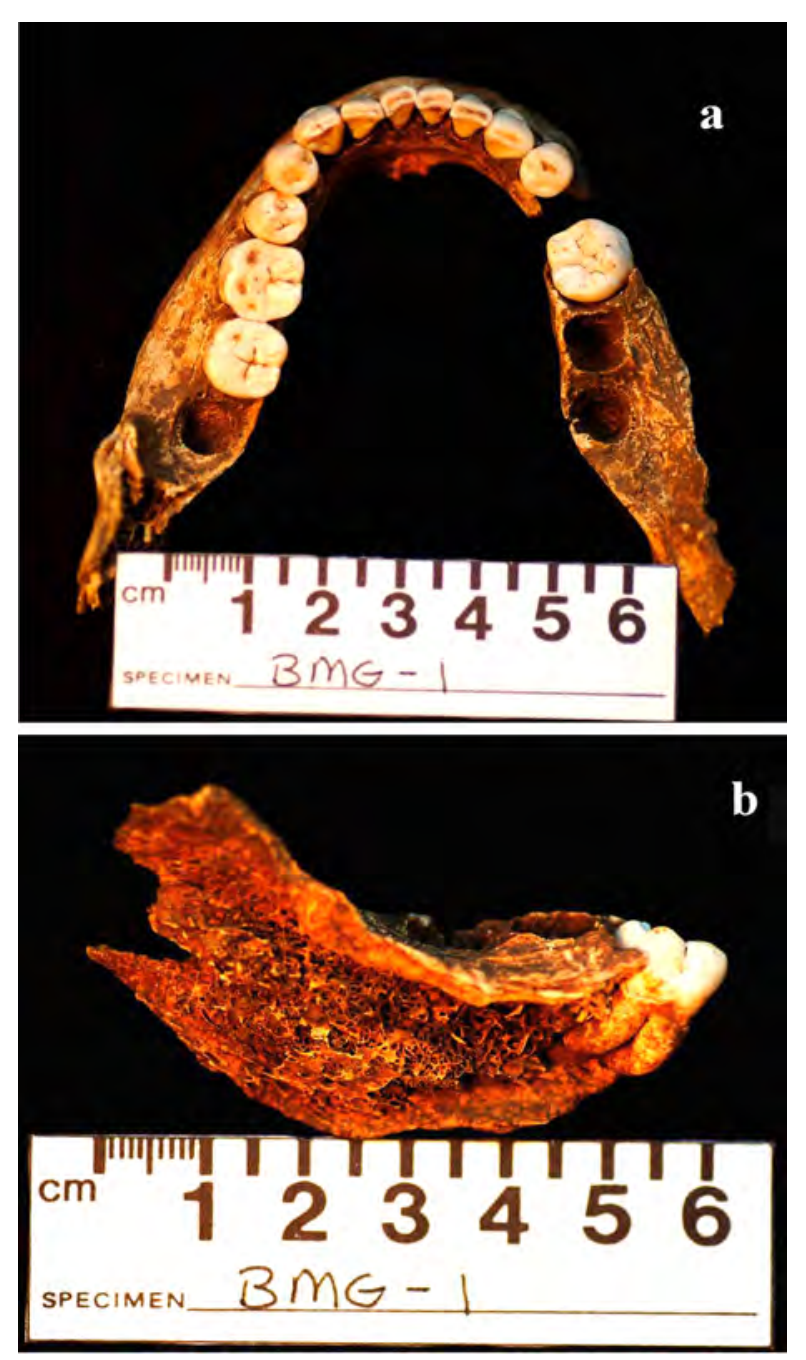

Fig. 1. Mandible of BMG-1. (a) Superior view of mandible and dental arcade with impacted $\mathrm{RM}_{1}$. Note wear differential between $\mathrm{LM}_{1}$ and $\mathrm{RM}_{1}$. $\mathrm{RP}_{4}$ was recovered but destruction of corpus precludes reattachment. (b)Lateral view of right corpus with $\mathrm{RM}_{1}$ exposed. It can be seen in this lateral view that the occlusal surface of $\mathrm{RM}_{1}$ is at the level of he alveolus even though the roots are fully formed. Scale in $\mathrm{cm}$.
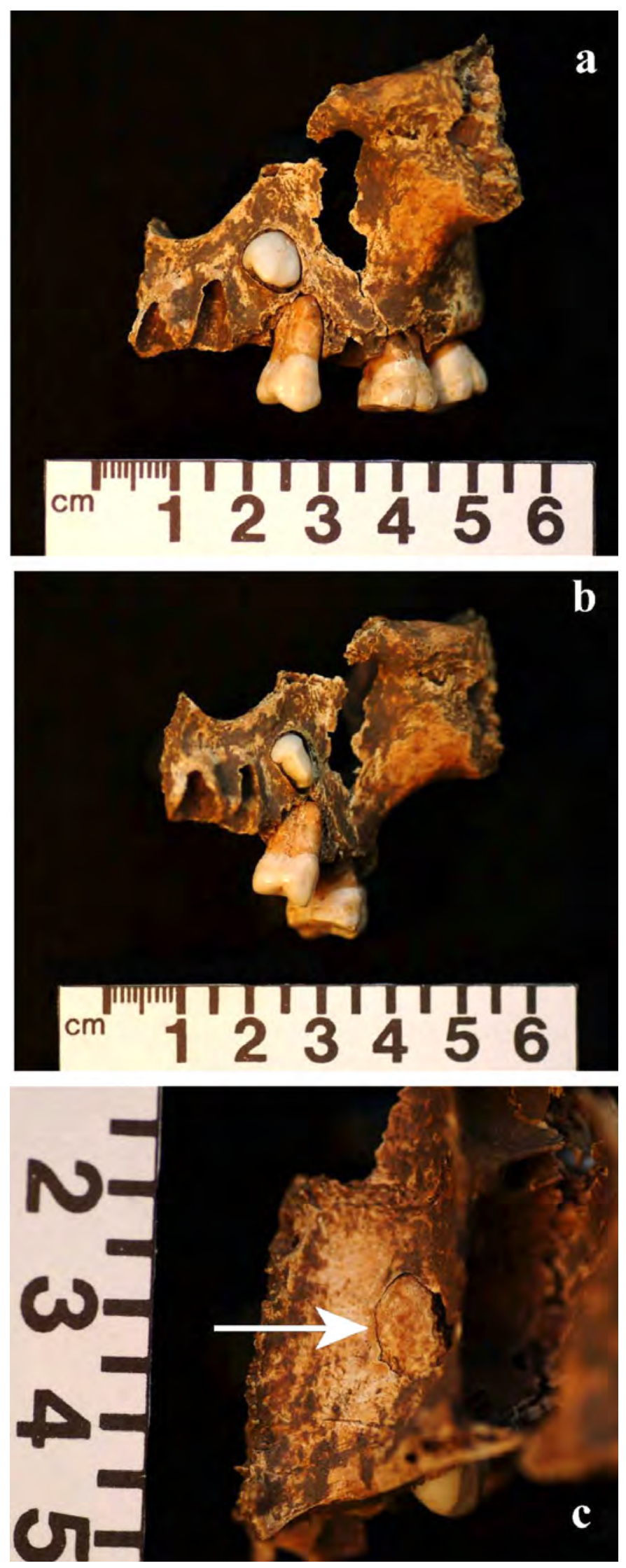

Fig. 2. Left maxilla of BMG-1. (a) Lateral view. (b) Anterior view. (c) Superior view, arrow points to canine root in floor of nasal cavity. Scale in $\mathrm{cm}$. 
of the missing molars are complete and there is a distal interproximal facet on $\mathrm{LM}_{2}$ indicating the third molars had fully erupted. Both rami are missing and the lateral outer table of the posterior right corpus has broken away revealing the cancellous bone.

The alveolar portion of the left maxilla (Fig. 2) is complete and retains the ectopically erupting $\mathrm{L}^{\mathrm{C}}$ and the $\mathrm{LM}^{1}$ and $\mathrm{LM}^{2}$. The $\mathrm{LP}^{3}$ is loose but fits into its partial socket while $\mathrm{LI}^{1}, \mathrm{LI}^{2}, \mathrm{LP}^{4}$, and $\mathrm{LM}^{3}$ are missing but were lost postmortem. The only remains of the right maxilla are the $\mathrm{RI}^{2}, \mathrm{R}^{\mathrm{C}}$, and $\mathrm{RP}^{3}$. Wear is moderate with dentine exposure on the lower incisors and dentine patches on the major cusps of the $\mathrm{LM}_{1}$ (Fig. 1a). Although extreme by modern standards for an individual of this age, advanced wear is common for prehistoric maize horticulturalists whose teeth were greatly impacted by grinding stone grit. The wear pattern for this individual is typical except for the almost complete lack of wear on the $\mathrm{LP}_{3}$ and $\mathrm{LP}_{4}$ which reflects the noneruption of the maxillary left canine and the corresponding gap in the maxillary arcade.

\section{Lower Right First Molar Impaction.}

The breakage of the posterior right mandibular corpus, although unfortunate as far as integrity of the remains is concerned, does allow visualization of the entire impacted right first molar (Fig. 1b). The tooth lies approximately $20^{\circ}$ off the vertical and appears to have been impacted against the RP4 although there are no contact facets on the distal root or crown of this tooth. Because of the position of the tooth within the corpus, the crown level with the alveolar border and the fact that there is no polish on the cusps, the tooth was probably never continually exposed to the oral environment. Although the corpus mesial to $\mathrm{RM}_{1}$ and distal to $\mathrm{RP}_{3}$ is broken and missing, both premolars appear to have erupted normally indicating that $\mathrm{rdm}_{2}$ was not retained, as can be common in $M_{1}$ impactions (Bjerklin and Kurol, 1983). The distal border of the RM socket exhibits some remodeling indicating that although the M1 had not erupted periodontal disease was causing minor resorptive bone loss.

\section{Upper Left Canine Ectopic Eruption.}

The canine is erupting through the alveolus between the roots of the $\mathrm{LI}^{2}$ and $\mathrm{LP}^{3}$ and is oriented perpendicular to the tooth row with the root appearing in the floor of the left nasal cavity (Fig. 2c). The sockets for the $\mathrm{LI}^{1}$ and $\mathrm{LI}^{2}$ are normal in form and position while the $\mathrm{LP}^{3}$ is rotated approximately $30^{\circ}$ distally. There is a gap between the $\mathrm{LI}^{2}$ and $\mathrm{LP}^{3}$ indicating that space was available for the $\mathrm{L}^{\mathrm{C}}$ had it been properly oriented (Fig. 2a, b). Additionally, the alveolus between the $\mathrm{LI}^{2}$ and $\mathrm{LP}^{3}$ is retained and shows no indication of $\mathrm{dl}^{\mathrm{C}}$ retention.

\section{DISCUSSION}

The appearance of anomalies of dental development and eruption in prehistoric skeletal series allows us to examine their occurrence outside of a clinical setting and can provide insight into their etiology and development. Although an in-depth examination of the ultimate cause of these anomalies is beyond the scope of this investigation an exploration into the occurrence of two anomalies in one individual might lend some insight into the developmental processes and genetic underpinnings of dental morphogenesis. Although prior research into cooccurrence shows little or no correspondence between ectopic canine eruption and M1 impaction (Baccetti, 1998, 2000) the possibility that similar genetic or developmental pathways lead to these positional anomalies is intriguing.

With BMG-1 we are presented with two instances of positional anomalies that do not appear to have been caused by common environmental perturbations such as retention of deciduous teeth or crowding. In both cases the original orientation of the tooth bud seems to have been rotated from its normal position causing the tooth to grow in the wrong direction. These cases of anomalous placement within the gnathic elements indicate disruption of the developmental pathway very early in embryogenesis possibly at the placode stage or even earlier when the cells that are to become the tooth bud are first differentiating (Thesleff, 2000, 2003). This implies that along the ectoderm/mesenchyme boundary at the point of contact between the signaling molecules (such as Shh) and their receptors and target genes there is a malfunction in the mechanism which orients the tooth in space. Whether the anomalous orientation is due to a breakdown in the cellular matrix and tissue structure or in the genetic signaling is unknown. One clue may be found in the observation that although within the dental arcade the axes of misorientation are different, labiolingual for the canine and mesio-distal for the molar, in space the axes are the same, i.e. antero-posterior with the crown directed anteriorly. This similarity in orientation in space may offer insight both into which element within the developmental genetic cascade involved in tooth formation misfires and whether these molar and canine positional anomalies are related etiologically.

If the misorientation of the two teeth is etiologically related then the failure could be due to several factors including, (1) a misalignment of the target cells within either the epithelial or mesenchymal tissue, depending on when in the genetic cascade it occurs (2) misorientation of the placode upon initial budding to the mesenchyme and (3) a kink in the epithelial/mesenchyme tissue complex within the already developing maxilla and mandible. It is also important to note that the crowns and roots of both teeth are normal, with cusps in the proper form and location, indicating no disruption of genetic communication after the initial budding of the placode to the mesenchyme or in the actual development of the tooth.

For the time being many questions concerning the ultimate cause of these positional anomalies must remain unanswered. However, insights gained from 
the case of BMG-1 may allow the focus to be narrowed down to a small developmental window early in tooth morphogenesis during the period at or before the placode buds to the mesenchyme. Because of the large number of signaling and target genes involved in the genetic cascade responsible for the earliest stages of dental development it may be difficult to pinpoint exactly which combination results in locating the developing tooth in space.

\section{ACKNOWLEDGEMENTS}

The author would like to thank Tony Largaespada and Mike Bremer of the Santa Fe National Forest as they were instrumental in all phases of our research in New Mexico.

\section{LITERATUR CITED}

Andreason JO, Petersen JK, Laskin DM, editors. 1997. Textbook and color atlas of tooth impactions. St. Louis: CV Mosby.

Baccetti T. 1998. A controlled study of associated dental anomalies. Angle Orthod 68:267-74.

Baccetti T. 2000. Tooth anomalies associated with failure of eruption of first and second permanent molars. Am J Orthod Dentofacial Orthop 118:608-610.

Bass WM. 1995. Human osteology: A laboratory and field manual, 4th edition. Columbia, Mo.: Missouri Archaeological Society.

Becker A, Chaushu S. 2000. Dental age in maxillary canine ectopia. Am J Orthod Dentofacial Orthop 117:657-662.

Bjerklin K, Kurol J. 1983 Ectopic eruption of the maxillary first permanent molar: Etiological factors. Am J Orthod 84:147-155.

Buikstra JE, Ubelaker DH. 1994. Standards for data collection from human skeletal remains. Fayetteville, Arkansas: Arkansas Archaeological Survey Research Series No. 44.

BurnettSE, Weets JD. 2001. Maxillary canine-first premolar transposition in two Native American skeletal samples from New Mexico. Am J Phys Anthropol 116:45-50.
Camilleri S, Lewis CM, McDonald F. 2008. Ectopic maxillary canines: Segregation analysis and a twin study. J Dent Res 87:580-583.

Chaushu S, Sharabi S, Becker A. 2003. Tooth size in dentitions with buccal canine ectopia. Eur J Orthod 25:485-491.

Crown PL, Orcutt JD, Kohler TA. 1996. Pueblo cultures in transition: The northern Rio Grande. In: Adler MA editor. The Prehistoric Pueblo world, A.D. 1150-1350. Tucson: University of Arizona Press, p 188-204.

Dachi SF, Howell FV. 1961. A survey of 3,874 routine full mouth radiographs. II. A study of impacted teeth. Oral Surg 14:1165-1169.

Ellis FH. 1988. From drought to drought: An archaeological record of life patterns as developed by the Gallina Indians of North Central New Mexico (A.D. 10501300). Santa Fe: Sunstone Press, 1988.

Grover PS, Lorton L. 1985. The incidence of unerupted permanent teeth and related clinical cases. Oral Surg Oral Med Oral Pathol 59:420-425.

Kramer RM, Williams AC. 1970. The incidence of impacted teeth. Oral Surg Oral Med Oral Pathol 29:237-241.

Nelson GC. 1992. Maxillary canine/third premolar transposition in a prehistoric population from Santa Cruz Island, California. Am J Phys Anthropol 88:135144.

Pindborg JJ. 1970 .Pathology of the dental hard tissues. Philadelphia: WB Saunders, 1970.

Peck S, Peck L, Kataja M. 1994. The palatally displaced canine as a dental anomaly of genetic origin. Angle Orthod 64:249-256.

Shah RM, Boyd MA, Vakil TF. 1978. Studies of permanent tooth anomalies in 7,886 Canadian individuals. J Canad Dent Assn 44:262-264.

Thesleff I. 2000. Genetic basis of tooth development and dental defects. Acta Odontol Scand 58:191-194.

Thesleff I. 2003. Developmental biology and building a tooth. Quintessence Int 34:613-620. 